\title{
Poverty in Europe by gender: the role of education and labour status
}

\author{
Rosa Aisa, Gemma Larramona, Fernando Pueyo
}

University of Zaragoza

\begin{abstract}
The objective of this paper is to analyze the determinants of poverty among workers in Europe by gender, using data for 25 countries obtained from the European Union Statistics on Income and Living Conditions (EU-SILC) database, for the period 2010 to 2013. The raw data show that the risk of poverty is similar for working men and women. Our study reveals that this homogeneity is only superficial; women should be in a relatively better position, since they have higher rates of tertiary education, but this advantage disappears when they access the market, because most part-time jobs are occupied by women. Asymmetries by gender are also present among occupations, but not between permanent and temporary workers.
\end{abstract}




\section{1.- Introduction}

The design of optimal policies to fight poverty, which are a key target of the Europe 2020 strategy, is complex, because those in poverty show a high degree of heterogeneity. Therefore, advances in research on specific groups in poverty become essential. This paper pursues a deeper understanding of the poverty among working people, from a gender perspective. The notion of in-work poverty - aka the working poor - is becoming central in economic debate, with a growing concern that employment does not always allow households and individuals to avoid poverty. However, this concern seems not to be associated with the feminization of poverty or the over-representation of women among the disadvantaged in terms of income. Looking at raw data from EU-SILC for 25 countries, for the period 2010 to 2013, income poverty, measured by the proportion falling below $60 \%$ of adjusted equivalent income, reaches $6.81 \%$ for working men and $6.77 \%$ for working women, a difference statistically insignificant. However, this paper establishes that the raw data hide different patterns between working men and women in terms of poverty.

Since our point is to discover whether the explanations of poverty for working men differ from those for working women, we focus on the prior research that links the labour force to the existence of a gender gap in terms of poverty. Among those studies that use cross-sectional data, Christopher et al. (2002) show that different combinations of labour market and welfare structures affect the gender gap in poverty: whereas in Sweden both reduce the feminization of poverty, in the Netherlands, the former widens the gender gap and the latter reduces it. In Australia, single full-time workers do not suffer a gender gap, although the welfare state has no effect on gender inequality in poverty, and in the rest of the analyzed countries ${ }^{1}$, neither the welfare state nor the labour market reduces gender gaps in poverty. Data are obtained from the fourth wave of the Luxembourg Income Study (LIS), years 1994-1995. The authors highlight

\footnotetext{
${ }^{1}$ Canada, France, Germany, United Kingdom and United States.
} 
four factors behind the gender gap in poverty: women's lower labour force participation, women's higher rates of part-time work, women's lower wages, and women's greater tendency to live with children. Therefore, generous income transfers are not enough to fight the gender gap in poverty, and policies that support women's employment and equal allocation of caregiving and employment among women and men are necessary.

The study of Wiepking and Maas (2005) is also based on the fourth wave of LIS, but extended to 22 industrialized countries. They do not find that higher social security benefits lead to a reduction in the feminization of poverty, but they do give support to the fact that differences in education play an important role in gender poverty asymmetry, explaining $13 \%$ of the gap, in such a way that authorities should make an extra effort to improve levels of education among women.

Using the fifth LIS data wave for 20 developed countries, Mandel and Semyonov (2005) establish that the key element in reducing differences in poverty between men and women is the wage structure. Although welfare policies are aimed at increasing female participation in the labour market, such participation is concentrated in jobs with lower wages, which leads to the feminization of poverty. Thus, occupational segregation is the key factor in explaining the gender gap in poverty. This result coincides with Lichtenwalter (2005), whose regression analysis utilizing data from the 2000 Census indicates that the gender gap in poverty detected in the 70 largest U.S. cities is mostly due to the over-representation of women in the lowest-wage occupations. However, Brady et al. (2010), using a similar sample to that employed by Mandel and Semyonov, do not find gender differences in poverty among workers, arguing that women are more likely to be poor if the family structure variables are omitted in the empirical analysis.

By incorporating the time dimension, Brady and Kall (2008) use data for 18 developed countries, from 1969 to 2000, obtained from LIS, applying pooled cross-sectional analysis. They 
find that the feminization of poverty is better explained by structural theory, which gives more weight to labour market and demographic variables than to welfare variables. In particular, they establish that the gender ratio in poverty depends negatively on the gender ratio of labour force participation and positively on the numbers of children in single-parent families. However, the proportion of women working part-time affects neither women's poverty nor the gender ratio in poverty. Bastos et al. (2009), using time data for Portugal, obtained from the European Community Household Panel Survey (1995-2001), find that unemployment or a temporary employment is the most important factor for higher rates of poverty among Portuguese women, although single-parenthood and the level of education also contribute.

In summary, the existing literature points to labour market characteristics, education, and family circumstances as possible explanations for the existence of gender differences in poverty in the working population. We examine these factors using data for 25 European countries, obtained from the EU-SILC database for the period 2010-2013 and, different from previous studies, we apply panel techniques. Several insights deserve to be highlighted. First, although women have higher levels of tertiary education than men, education is less of a protection against poverty for women. This surprising result is explained by differences in labour market participation: women are over-represented in part-time jobs and certain disadvantaged occupations, such as Elementary. Thus, our study confirms prior evidence about the importance of the labour market structure to explain women's poverty, and, what is new, it identifies which labour market characteristics are more damaging to women. Having a temporary job does not introduce asymmetries by gender in terms of poverty. In contrast, occupational segregation does involve a gender gap in poverty. The higher proportion of women in Elementary occupations puts women as a whole at a disadvantage, although some advances are observed, considering that sectors associated with lower probabilities of poverty, such as the Professions, are feminized. In any case, having a part-time job is more influential in explaining poverty in working women. 
Interestingly, our estimations reveal that the individual predicted probability of poverty is higher for men working part-time than for women working part-time, when the rest of the variables are controlled for. However, since women occupy most part-time jobs, the average predicted probability of poverty among those who have a part-time job is higher for women.

Section 2 of the paper presents the dataset, some descriptive statistics, and the methodology used. Section 3 shows the main empirical findings based on the econometric analysis, and Section 4 outlines our conclusions.

\section{Methodology and dataset}

Our analysis is based on panel data from 25 European countries in the EU-SILC database of longitudinal data for the 2010-2013 period: Austria, Belgium, Bulgaria, Cyprus, Czech Republic, Denmark, Estonia, Finland, France, Hungary, Ireland, Iceland, Italy, Lithuania, Luxembourg, Latvia, Malta, the Netherlands, Norway, Poland, Portugal, Slovenia, Slovak Republic, Spain, and the United Kingdom. The database provides unbalanced panel data, and "is an instrument aiming at collecting timely and comparable cross-sectional and longitudinal multidimensional microdata on income, poverty, social exclusion and living conditions. Longitudinal data pertaining to individual-level changes over time, observed periodically over a four-year period.”

We have chosen to use the most well-known income poverty measure, the EU at-risk-ofpoverty index, defined as the share of individuals with an equalized disposable income, after social transfers, less than $60 \%$ of the national median equalized disposable income. The equalized disposable income includes all monetary income received from any source by each member of a household. This includes income from work, investment, and social benefits, plus 
any other household income; taxes and social contributions paid are deducted from this sum and the resulting value is divided by the number of 'equivalent adults'. A standard equivalence scale, the modified OECD scale, is used to give a weight to all members of the household: 1.0 to the first adult, 0.5 to the second, and each subsequent individual aged 14 and over, and 0.3 to each child under age 14. This is a binary variable with one value for those with an equalized disposable income less than $60 \%$ of the national mean in the year, and value 0 for the rest.

It is clear that gender will receive our primary attention, but we include those factors which appear to affect poverty, as pointed out by prior research as independent variables: owner of a house (measured by a dummy variable with value 1 for those living in a free house or owners without mortgage); age (measured by five categories: range 18-25, range 26-35, range 36-45, range 46-55 and age 56-65); family structure (measured by civil status, that is, single, married, divorced, widowed, and separated); dependent children (that is, those living with children under age 18 or those paying alimony), health (measured by perceived health), education, and labour market characteristics. Our interest focuses on the two latter sets of variables. We also include country dummies in order to account for the specific welfare state and other country characteristics.

Education is measured by a categorical variable with three levels: primary, secondary, and tertiary education. In turn, labour status is covered by three variables: type of job - depending on the contract (full time or part time) and on the duration (temporary or permanent jobs) - and type of occupation, following the ten aggregate ISCO categories (armed forces, managers, professionals, technicians, clerical support, services and sales, primary sector skilled, craft and trade, plant and machine, elementary).

We estimate the determinants of poverty among males and females using a logistic model for panel data with random effects. 


\section{The sample}

Our sample includes those individuals working in the labour market, after dropping other collectives (unemployed, retired, those doing housework, and inactive individuals) from the original EU-SILC sample. Then, our sample has 281,056 observations, 50.15\% male and 49.85\% female. Our sample's main characteristics are depicted in the bar diagrams in Figure 1 (including dots with information about the probabilities predicted from our estimation, discussed in Section 3).

By age (Figure 1a), most observations are included in the intermediate ranges: $28 \%$ in the interval 36-45 and $28.6 \%$ in the interval 46-55, with a slightly higher representation of women, $21.8 \%$ and $7.3 \%$ are in the $26-35$ and $18-25$ intervals, respectively, and the remaining $14.3 \%$ is older than 56, with a slightly higher presence of men in those three cases. By civil status (Figure 2a), most individuals are married (59.9\% of males and $57 \%$ of females) or single (33\% and $28.2 \%$, respectively), $5.1 \%$ of males and $10.2 \%$ of females are divorced, with lower numbers for those who are separated or widowed. The distribution of health is quite homogeneous, with around 54\% and 25\% reporting "good” or "very good” health, respectively. About $17 \%$ indicate having "fair" health, with less than 3\% reporting "bad” and "very bad” health (Figure 1c).

The distribution of the sample by education level reveals gender differentials indicating that women have a higher level than men, on average (Figure 1d). It is noteworthy that, while $30 \%$ of the men have tertiary education, almost $39 \%$ of the women have that level. In contrast, the presence of those with only secondary and primary education is lower among women $(46.2 \%$ and $15 \%$, respectively, against $51.4 \%$ and $19.7 \%$ among men).

For the labour market, Figure 1e reveals that temporality has a slightly higher incidence in female jobs (13\% of contracts, 1.2 points higher than among men), but the main asymmetries 
appear when differentiating between full-time and part-time contracts: while part-time contracts are only $5.1 \%$ of the total among men, the proportion more than quadruples for women, reaching $22.4 \%$.

Some gender differences are also seen in the distribution of occupations. Setting aside the three occupations with the lowest representation in the sample (Armed forces, Managers, and, especially, Primary sector skilled jobs), and another with almost parity (Technicians, about a sixth of the sample), Figure 1f shows four occupations with a relatively higher presence of women and two that are strongly dominated by men. The 'Feminized' occupations are Professionals (22.6\% of women, against $15.3 \%$ of men), Services and sales $(20.4 \%$ against 9.8\%), Clerical support (14.8\% against 6.2\%) and Elementary jobs (11.8\% against 7.8\%). In the two remaining categories, the prevalence of men is even higher: $19.7 \%$ in Craft and trade and 13.6\% in Plant and machine, occupations in which the presence of females is below 3.5\%.

\section{Determinants of poverty by gender: a panel analysis}

According to the EU at-risk-of-poverty index, the incidence of poverty in the sample is $6.8 \%$ and the difference by gender is negligible (0.04 points). Does this mean that poverty affects women and men in the same way? The description of the sample reveals asymmetries by gender in several characteristics, mainly evident in the labour market variables. In what follows, we set out to identify the role of each variable on poverty and the possible differential influences on men and women.

Table 1 presents the estimations of our model for both male and female, providing the ratios associated with each explanatory variable and its level of significance.

The figures related to owning a house or having no mortgage confirms that such circumstances reduce the probability of poverty by $10 \%$, for both male and female. Previous 
studies, in particular Fusco et al. (2010) and Ayllón and Fusco (2017), give no conclusive evidence about the effect of housing tenure status on poverty, probably because of the very different samples used in their analyses. Age appears to be a preventative factor (as in Wiepking and Maas, 2005; Mandel and Semyonov, 2005; Brady et al., 2010); in general, the probability of being in poverty is reduced for each subsequent age interval (with the exception of males aged 46-55 and females aged 36-45). The probability of being in poverty for men over age 56 is reduced by $56 \%$, and in the case of women, the reduction exceeds $75 \%$. One reason is that experience and promotion opportunities increase with age. Furthermore, the worsening labour market conditions in the last years also contributes to the worst position of younger workers.

With respect to civil status, most men (married, single, or widowed) are less affected by economic problems. Those who are separated have a probability of being in poverty that is $50 \%$ higher, and for the divorced the probability is $66.5 \%$ higher. Women who are married are in the best position, with a significant advantage over single women. The remaining situations for women involve a higher risk of poverty than being married: $38.6 \%$ higher for widows, $90.9 \%$ higher for those who are divorced, and higher still for women who are separated (Ayllón and Fusco, 2017, also find that being divorced is positively related to poverty).

Having dependents or paying alimony has no significant effects (as in Wiepking and Maas, 2005). It seems that its positive influence on poverty is captured by other variable, namely the number of dependents, with an important impact on both men and women. In contrast, health appears to be an important factor in protecting against poverty: for the five levels considered, the probability of poverty among women with the worst health is twice that of those with the best health status, while among men this probability increases 2.3 times. This result is different from the evidence found by Fusco et al. (2010) and Ayllón and Fusco (2017), where bad health does not seem to be related to poverty. A possible explanation is that these authors distinguish only between having bad health or not, whereas we discern five categories. The direction of causality, 
i.e., whether ill health causes poverty or becoming poor causes bad health, should also be considered.

\section{Education}

Previous literature points out education as protection against poverty (Wiepking and Maas, 2005; Mandel and Semyonov, 2005; Bastos et al., 2009; Brady et al., 2010). As expected, we also find that education and poverty are negatively related: each successive level of education leads to a significant reduction in the incidence of poverty then the level immediately below. In the case of men, taking those with primary education as reference, completing secondary or tertiary reduces their risk of being poor by $68.5 \%$ and $83.8 \%$, respectively. The differences are less significant for women; those with secondary and tertiary education face a probability of poverty of $48.9 \%$ and $74.3 \%$ lower than those with only primary, respectively. Why education appears to protect women against poverty to a lesser extent is not exactly clear. Our hypothesis is that there is a positive relationship between education and income that manifests itself through participation in the labour market, and that such participation has different consequences for men than for women.

\section{Labour market}

Setting aside the country effects, the three remaining variables in our estimation are related to the labour market. The first differentiates between full-time and part-time jobs, and not surprisingly, the results confirm that part-time jobs are associated with a higher risk of poverty; 4.5 times higher for men and 3.1 times for women. The second compares permanent and temporary jobs, with the result that the latter increases the probability of poverty 5.7 times for men and 4.6 times for women. Thus, these job characteristics are revealed to be key determinants of the economic situation of workers, as in some previous evidence (Christopher et al. 2002; Bastos et al. 2009). However, Lichtenwalter (2005) does not find a significant association 
between gender disparities in the poverty rates and the percent of females of all full-time workers, giving as explanation the limited workforce participation of married women who avoid poverty due to their spouses' income.

The third labour market variable, the type of occupation, also involves an important degree of heterogeneity. The Armed forces, Managers, and Professionals appear as the three occupations with the lowest risks (this outcome is in line with the work of Mandel and Semyonov, 2005, who show that working in a managerial position increases significantly workers' earnings). Technicians and Clerical support add to this group in the case of women, although at double and quadruple levels of risk, respectively, in the case of men. The remaining occupations are associated with significantly higher probabilities of poverty. Men working in Plant and machinery, Craft and trade, and Services and sales have a 6 to 8 times higher probability than the first group, while these figures increase to 10 to 17 times in the case of women. The two remaining occupations put workers in the worst position: Primary sector skilled multiplies the risk of poverty by $22.6 \%$ and $26.2 \%$ for men and women, respectively, although, as we have shown, this is a category with a low representation in the sample. The other, with a more important representation, is Elementary occupations, where men face a risk of being in poverty that is 20 times higher than the first group, and the risk for women is 40 times higher.

The great heterogeneity in the various positions in the labour market with a significant influence on poverty in some cases, which, in turn, is not homogeneous between men and women, reveals the key role played by the labour market in considerations of the explanation of poverty. For a better understanding of these issues, we analyze the predicted probabilities for each status derived from our estimations.

\section{Predicted probabilities}


Note that the figures in Table 1 report the relative influence of the different status of every variable, taking one of them as reference, but, since this is done separately for women and men, direct comparisons between gender are not allowed. Predicted probabilities overcome this limitation by providing the (absolute) probability of poverty that is attributed to each status of the variables, both for women and men, making comparisons possible, as shown in Table 2 and depicted as dots in the diagrams of Figure 1.

Apart from the (in general) inverse relationship between age and poverty, Figure 1a shows a higher risk of poverty for women than for men in young and medium-age individuals, but a higher risk for men at the oldest age. Married men are the only collective in a worse position than women in the same civil status (Figure $1 \mathrm{~b}$ indicates probabilities of $1.5 \%$ and $0.9 \%$, respectively). In the rest of the situations, the risk is always higher for women, with a maximum of almost 2.7 points higher, in the case of those who are separated. The probabilities associated with health are quite similar for both men and women, never exceeding a quarter of a point.

The message emerging from the predicted probabilities by education (Figure 1d) confirms that, although education plays a role in protecting from poverty, the protection is less effective in women than in men. The risk of poverty diminishes more quickly among men, while women with secondary and tertiary education face a level of risk about one third higher than men. To encompass both indicators (the differences in the weight in the sample and in the predicted probabilities), Figure 2 shows the composition of the average probability that the model attributes to education, namely, the sum of the probabilities for each category, weighted by its representation in the sample. The average predicted probability for men is $1.2 \%$, of which $13.4 \%$ is due to men with tertiary education and the rest is distributed similarly (around $43 \%$ each) among men with primary and secondary. In the case of women, the average predicted probability is slightly higher, at $1.3 \%$, but its composition is quite different $-22.3 \%$ by women with the highest education (in part due to the higher representation in the total compared with men, in part 
due to the higher risk of poverty), $49.3 \%$ by women with secondary, and only $28.4 \%$ by women with primary. Thus, poverty is almost two times more related to tertiary education among women than among men.

This asymmetry is related to the differential performance of gender in the labour market. We do not pay attention to the differentiation between permanent and temporary jobs, because the distribution (and the predicted probabilities) is quite homogeneous between men and women. However, as stated earlier, women have a higher representation among part-time contracts, related to significantly lower wages. The difference reaches the maximum in the Netherlands, where part-time contracts represents a 79\% among women against an 18\% among men. Approximately half of women in Belgium, Austria, Ireland, Luxemburg and UK are also occupied in part-time jobs, around a third in Denmark and France and around a 25\% in Italy, Spain and Island. In all the countries these weights are significantly higher than for men. On the whole sample, part-time jobs amount for a $21.5 \%$ of contracts among women, against $5.3 \%$ in the case of men. Predicted probabilities in Figure 1e complement this information: the risk of poverty for women in such situations is lower than for men, apparently compensating for their over-representation. Figure 2b indicates that such compensation does not hold for all. The model assigns probabilities of $1.4 \%$ and $1.5 \%$ to this characteristic of jobs for men and women, respectively. While only $15.3 \%$ of this risk is related to part-time jobs in the case of men, this figure increases to $43.4 \%$ for women.

We found above a higher contribution of the highest level of education to poverty among women. The higher proportion of part-time jobs among women is an element underlying this outcome, what is clear from Figure 3a: the number of women with the highest education level engaged in part-time jobs is almost 5 times the number of men in such situation.

As stated above, another source of heterogeneity is the distribution among occupations. Predicted probabilities in Figure 1f complete the explanation. Let us set apart the Primary sector 
skilled, because, although it is related to some of the highest probabilities of poverty, it has a low representation in the sample. With this exclusion, Elementary appears as the occupation associated with a higher risk of poverty, about two times that of the next set of occupations ordered by risk (Services and sales, Craft and trade, Plant and machinery). Clerical support occupies a third row of importance, while the remaining occupations (Technicians, Professionals, Managers and Armed forces) are associated with significantly lower probabilities of poverty, apart from very small differences by gender.

Elementary activities occupy more women than men, and a higher predicted probability for women strengthens their lowest position. Although exhibiting lower risks of poverty, a similar situation exists among workers in Services and sales. Clerical support is the other highly feminized occupation, but in this case the risk of poverty is higher for men, which compensates partially for the asymmetry. Craft and trade and Plant and machinery appear as highly masculinized; the attribution of probability by the model for each of them is different: higher for women in the former, higher for men in the latter. In order to shed light on this mixed relationship in terms of occupation and predicted probabilities, we repeat the exercise carried out for education and type of job, by decomposing the average probability of poverty attributed to the type of occupation, among all of the categories. Figure 2c offers a clearer picture. The probability attributed to occupation is $1.1 \%$ for both men and women. However, Elementary occupations are responsible for $39.1 \%$ of this probability in the case of women, against only 23.4\% for men. The contribution of Services and sales is also somewhat higher for women at $30 \%$, more than double that the level for men. In contrast, the highest contributions in the case of men appear in Craft and trade and Plant and machinery (25.5\% and $16.9 \%$ of average probability, respectively; in both cases about five times the importance for women). These four occupations account clearly for the main differences by gender. 
Is there a penalty in these occupations for the more educated workers, as found in part-time contracts? Figure 3c shows no evidence for that. In the whole sample, females with tertiary education have a higher representation in Services and sales and, to a lesser extent, in Elementary; in turn, men have a higher representation in Craft and trade and Plant and machinery. In aggregate, the number of males and females in these four occupations is similar. It is true that there are twice as many females as males in Elementary, which exhibits the highest probability of poverty, but its low importance seems far from justifying the highest rates for more educated people found in the case of females. All in all, the lower protection against poverty given by education seems related to a higher proportion of part-time jobs among the most educated women, rather than a bias in other characteristics of the job.

\section{Conclusions}

The raw data show that the incidence of poverty among workers in Europe is similar for men and women. However, some gender-based differences arise immediately when we pay closer attention to the data considering demographic, educational, or socio-economic variables. These asymmetries motivate our analysis of the determinants of poverty by gender, which is carried out by estimating the same logit model separately for men and women.

Since the economic situation of individuals is mainly determined by the characteristics of their occupation and, in general, a higher level of education is related to jobs with higher wages, we pay special attention to these variables and their performance by gender. Indeed, we find that education is an element that prevents workers falling into poverty, but that such protection is less effective for women, since women with tertiary education retain a higher probability becoming poor. Our analysis confirms that certain differences appear at entry to the labour market of both men and women, which leads to a different relationship between education and labour income. 
Three characteristics of the labour market have been considered: the temporary (or not) nature of jobs, the classification by occupations, and whether the job is full-time, or not. The former appears not to be relevant in our analysis, since although temporary jobs increase the risk of poverty, neither their relative importance nor the probability predicted by the model shows significant differences by gender. The distribution of occupations by gender is, however, heterogeneous. We have identified two sectors that are highly masculinized: Craft and trade and Plant and machinery, and four that are highly feminized: Professionals, Services and sales, Clerical support, and Elementary. The probability of poverty is low for Professionals and is the highest for Elementary, double the risk in the four remaining occupations, which occupy intermediate positions. In summary, the main differences in the exposure to poverty come from the fact that more than half of the probability of poverty associated with occupation is due to Elementary and Services and sales, in the case of females, while the activities that have the most negative potential for males are Plant and machinery and Craft and trade. Despite this, we have not identified a particular bias related to education, although the total numbers of men and women engaged in occupations with elevated risk are quite similar.

The higher incidence of poverty among educated women than among educated men is explained by the third characteristic of the jobs considered, that is, having a full-time or part-time job. The latter, obviously, involve lower wages and are clearly feminized; less than a fifth or individuals engaged in such jobs are male. Thus, this is a feature of the labour market that increases the risk of poverty for women. Furthermore, the weight is similar when considering only workers with tertiary education - four out of five are female. Besides the waste of human capital, this implies a significantly higher exposure to poverty for educated women that matches the differences by gender in poverty statistics by education.

In summary, although the incidence of poverty is similar in men and women, the homogeneity is apparent. A higher level of education puts women in a better position for entry to 
the labour market, with a higher proportion of part-time jobs, which compensates for the initial advantage. This finding reinforces the importance of - and need for - policies aimed at ensuring an adequate inclusion of women in the labour market. Although our analysis also provides support to the positive effect of promoting education among women, women's educational improvement appears to be a necessary, but insufficient, condition. Therefore, the efficiency of social spending devoted to ensuring that women have an adequate standard of living should give priority to active measures to promote the labour-market participation of women.

Labour laws in the EU protect adequately women's rights and avoid gender wage gaps. However, we have still identified some gender asymmetries that deserve policy attention. Specifically, the focus should be put on part-time jobs, mostly occupied by women. Either chosen voluntary or not, part-time jobs implies an income penalty that increases poverty risks for women. Obviously, the problem is harder when part-time work is not an election. However, when it is voluntary it is usually related to domestic work and care occupations, like children care. These occupations rely mainly on women and can limit their options when they re-enter into the labour market or try to access to a full-time job. Thus, some policy efforts appear to be still necessary to promote a more symmetric distribution of care occupations by gender and a better reconciliation of motherhood and professional life. 


\section{References}

Ayllón, S., Fusco, A. (2017): Are income poverty and perceptions of financial difficulties dynamically interrelated? Journal of Economic Psychology 61, 103-114

Bastos, A., Casaca, S.F., Nunes, F., Pereirinha, J. (2009): Women and poverty: a gendersensitive approach. The Journal of Socio-Economics 38, 764-778

Brady, D., Kall, D. (2008): Nearly universal, but somewhat distinct: The feminization of poverty in affluent Western democracies, 1969-2000. Social Science Research 37, 976-1007

Brady, D., Fullerton, A. S., Cross, J. M. (2010): More Than Just Nickels and Dimes: A CrossNational Analysis of Working Poverty in Affluent Democracies. Social Problems, 57, 4, $559-585$

Christopher, K., England, P., Smeeding, T.M., Ross Phillips, K. (2002): The Gender Gap in Poverty in Modern Nations: Single Motherhood, the Market, and the State. Sociological Perspectives 45, 219-42

Fusco, A., Guio, A. C., Marlier, E. (2010): Characterising the income poor and the materially deprived in European countries. In Income and living conditions in Europe., Anthony B. Atkinson and Eric Marlier editors. Eurostat Statistical books. ISBN 978-92-79-16351-7. doi:10.2785/53320

Mandel, H., Semyonov, M. (2005): Family Policies, Wage Structures, and Gender Gaps: Sources of Earnings Inequality in 20 Countries. American Sociological Review 70, 949-967

Lichtenwalter, S. (2005): Gender Poverty Disparity in US Cities: Evidence Exonerating FemaleHeaded Families. The Journal of Sociology \& Social Welfare 32, 2, 75-95

Wiepking, P., Maas, I. (2005): Gender Differences in Poverty: A Cross-National Study. European Sociological Review 21, 187-200 
Table 1. Panel logistic regressions: odd ratios

\begin{tabular}{|c|c|c|c|c|c|c|}
\hline \multirow[b]{2}{*}{ owner or free house } & \multicolumn{3}{|c|}{ male } & \multicolumn{3}{|c|}{ female } \\
\hline & 0.8920771 & 0.033 & $* *$ & 0.8984327 & 0.048 & $* *$ \\
\hline \multicolumn{7}{|l|}{ Age $18-25$ (ref) } \\
\hline $26-35$ & 0.6447214 & 0 & $* * *$ & 0.4758795 & 0 & $* * *$ \\
\hline $36-45$ & 0.5239964 & 0 & $* * *$ & 0.5697696 & 0 & $* * *$ \\
\hline $46-55$ & 0.579304 & 0 & $* * *$ & 0.3969401 & 0 & $* * *$ \\
\hline $56-65$ & 0.4397159 & 0 & $* * *$ & 0.2422374 & 0 & $* * *$ \\
\hline \multicolumn{7}{|l|}{ Never married (ref) } \\
\hline Married & 1.066554 & 0.326 & & 0.4211863 & 0 & $* * *$ \\
\hline Separated & 1.498284 & 0.046 & $* *$ & 3.004769 & 0 & $* * *$ \\
\hline Widowed & 1.433721 & 0.21 & & 1.386395 & 0.015 & $* *$ \\
\hline Divorced & 1.665028 & 0 & $* * *$ & 1.908955 & 0 & $* * *$ \\
\hline Dependents or alimony & 1.051169 & 0.477 & & 0.8994613 & 0.157 & \\
\hline Number of dependents & 2.042472 & 0 & $* * *$ & 1.557134 & 0 & $* * *$ \\
\hline \multicolumn{7}{|l|}{ Very good health (ref) } \\
\hline Good health & 1.126365 & 0.018 & $* *$ & 1.159323 & 0.005 & $* * *$ \\
\hline Fair health & 1.400513 & 0 & $* * *$ & 1.567279 & 0 & $* * *$ \\
\hline Bad health & 1.585971 & 0 & $* * *$ & 1.751782 & 0 & $* * *$ \\
\hline Very bad health & 2.306718 & 0.009 & $* * *$ & 2.022199 & 0.014 & $* *$ \\
\hline \multicolumn{7}{|l|}{ Primary education (ref) } \\
\hline Secondary education & 0.3148895 & 0 & $* * *$ & 0.5113283 & 0 & $* * *$ \\
\hline Tertiary education & 0.1620139 & 0 & $* * *$ & 0.2570065 & 0 & $* * *$ \\
\hline \multicolumn{7}{|l|}{ Full-time (ref) } \\
\hline Part-time & 4.47985 & 0 & $* * *$ & 3.138927 & 0 & $* * *$ \\
\hline \multicolumn{7}{|l|}{ Permanent job (ref) } \\
\hline Temporary job & 5.659227 & 0 & $* * *$ & 4.641629 & 0 & $* * *$ \\
\hline \multicolumn{7}{|l|}{ Armed forces (ref) } \\
\hline Managers & 1.125639 & 0.702 & & 1.944117 & 0.522 & \\
\hline Professionals & 1.515179 & 0.155 & & 2.625488 & 0.347 & \\
\hline Technicians & 2.039113 & 0.013 & $* *$ & 3.514848 & 0.22 & \\
\hline Clerical support & 4.014963 & 0 & $* * *$ & 5.091584 & 0.113 & \\
\hline Services and sales & 7.893922 & 0 & $* * *$ & 15.78768 & 0.007 & $* * *$ \\
\hline Primary sector skilled & 22.64146 & 0 & $* * *$ & 26.16453 & 0.002 & $* * *$ \\
\hline Craft and trade & 7.482782 & 0 & $* * *$ & 16.3323 & 0.007 & $* * *$ \\
\hline Plant and machinery & 6.111351 & 0 & $* * *$ & 10.3456 & 0.023 & $* *$ \\
\hline Elementary & 20.28229 & 0 & $* * *$ & 39.95614 & 0 & $* * *$ \\
\hline Country dummies & Yes & & & Yes & & \\
\hline _cons & 0.0033905 & 0 & $* * *$ & 0.0014935 & 0 & $* * *$ \\
\hline No obs. & 140949 & & & 140107 & & \\
\hline $\begin{array}{l}\text { LR. Test of rho=0 } \\
\text { (Prob }>=\text { chibar2) }\end{array}$ & 0.000 & & & 0.000 & & \\
\hline
\end{tabular}


Table 2. Panel logistic regressions: predicted probabilities

\begin{tabular}{|c|c|c|}
\hline & \multirow[b]{2}{*}{ male } & \multirow[b]{2}{*}{ female } \\
\hline & & \\
\hline No owner nor free house & 0.0153287 & 0.0164863 \\
\hline Owner or free house & 0.0139665 & 0.0150593 \\
\hline $18-25$ & 0.0217513 & 0.028202 \\
\hline $26-35$ & 0.0152796 & 0.0152787 \\
\hline $36-45$ & 0.0128842 & 0.0177966 \\
\hline $46-55$ & 0.0139966 & 0.0130718 \\
\hline $56-65$ & 0.0111342 & 0.0084543 \\
\hline Never married & 0.0138907 & 0.0193244 \\
\hline Married & 0.0146391 & 0.0090266 \\
\hline Separated & 0.0192342 & 0.0466408 \\
\hline Widowed & 0.0185725 & 0.025389 \\
\hline Divorced & 0.0209074 & 0.0328699 \\
\hline Without dependents & 0.014238 & 0.0166058 \\
\hline With dependents & 0.0148296 & 0.0151884 \\
\hline Very good health & 0.012959 & 0.0131395 \\
\hline Good health & 0.0142878 & 0.014913 \\
\hline Fair health & 0.017049 & 0.0192103 \\
\hline Bad health & 0.0188358 & 0.0210551 \\
\hline Very bad health & 0.0252932 & 0.0236638 \\
\hline Primary education & 0.0264049 & 0.0242974 \\
\hline Secondary education & 0.009917 & 0.0136846 \\
\hline Tertiary education & 0.0054838 & 0.0073635 \\
\hline Full-time job & 0.0123039 & 0.0107759 \\
\hline Part-time job & 0.0412807 & 0.028506 \\
\hline Permanent job & 0.0086789 & 0.0100102 \\
\hline Temporary job & 0.0384259 & 0.0375693 \\
\hline Armed forces & 0.0023629 & 0.0011823 \\
\hline Managers & 0.0026406 & 0.0022738 \\
\hline Professionals & 0.0034869 & 0.0030485 \\
\hline Technicians & 0.0045949 & 0.0040449 \\
\hline Clerical support & 0.0085386 & 0.0057747 \\
\hline Services and sales & 0.0155635 & 0.0165853 \\
\hline Primary sector skilled & 0.0378226 & 0.0259926 \\
\hline Craft and trade & 0.014853 & 0.0171016 \\
\hline Plant and machinery & 0.0124296 & 0.0112598 \\
\hline Elementary & 0.0345833 & 0.0373672 \\
\hline
\end{tabular}


Figure 1. Composition of the sample (bars, left scale) and predicted probabilities (dots, right scale)

1a. Age

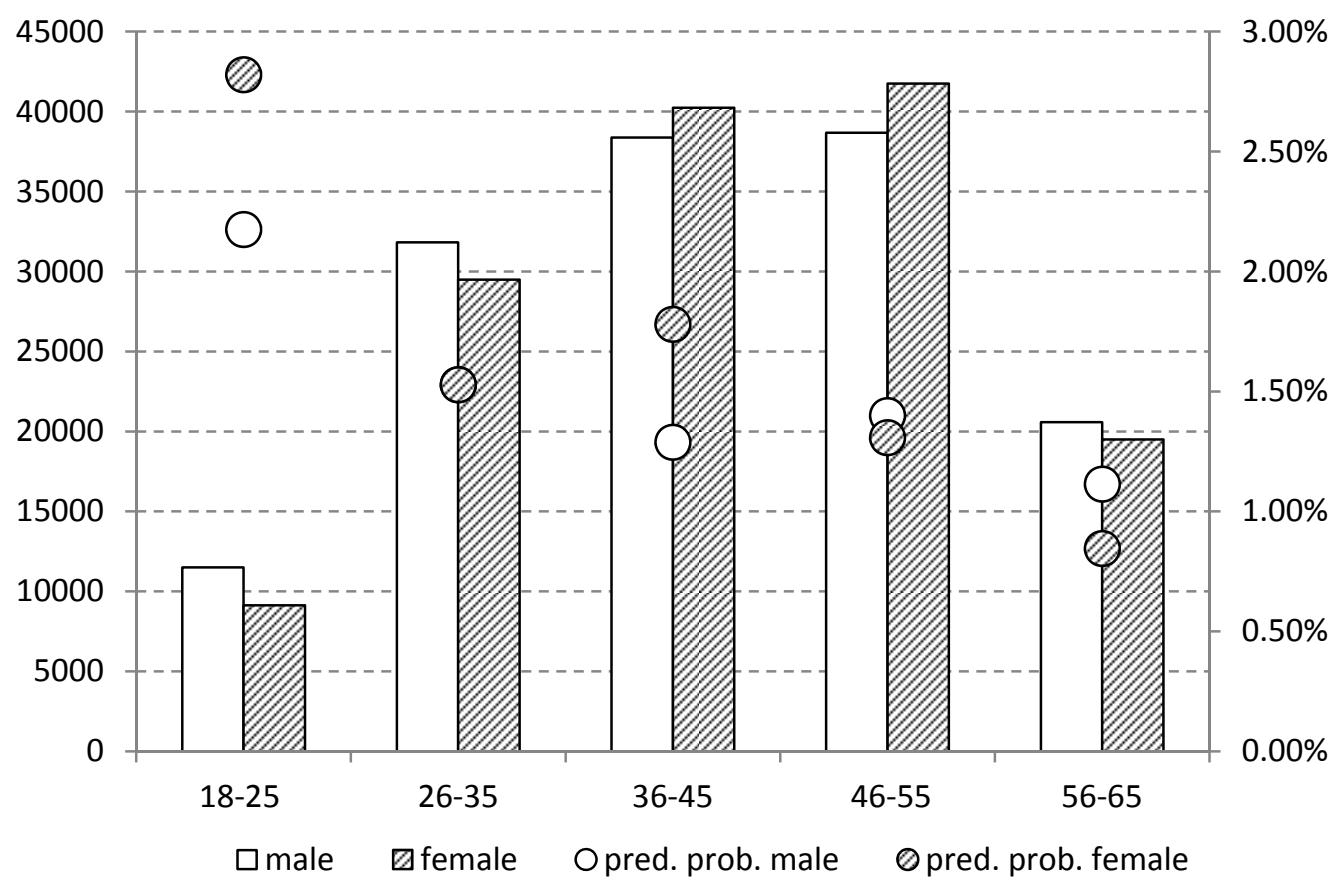

1b. Civil status

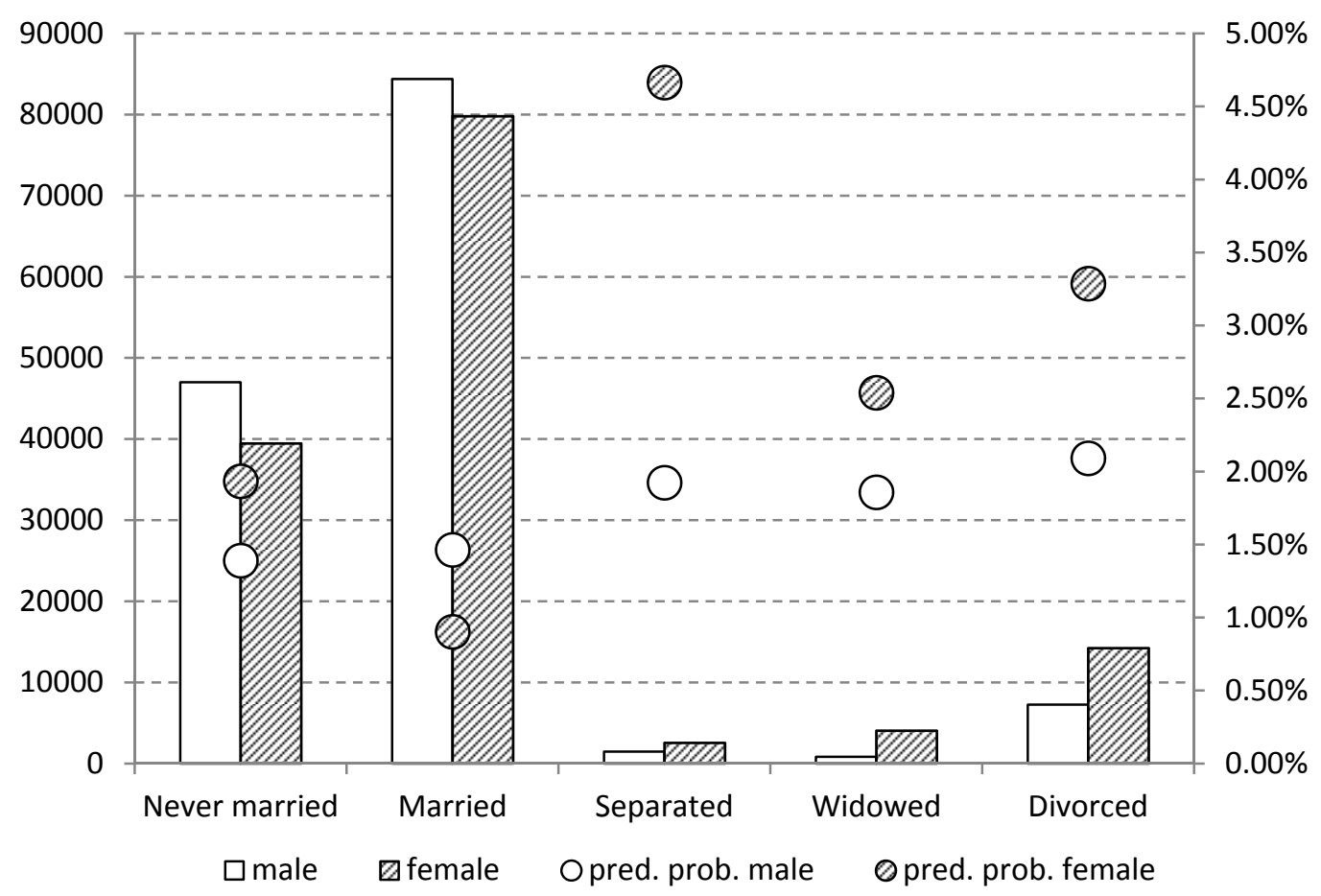


1c. Health

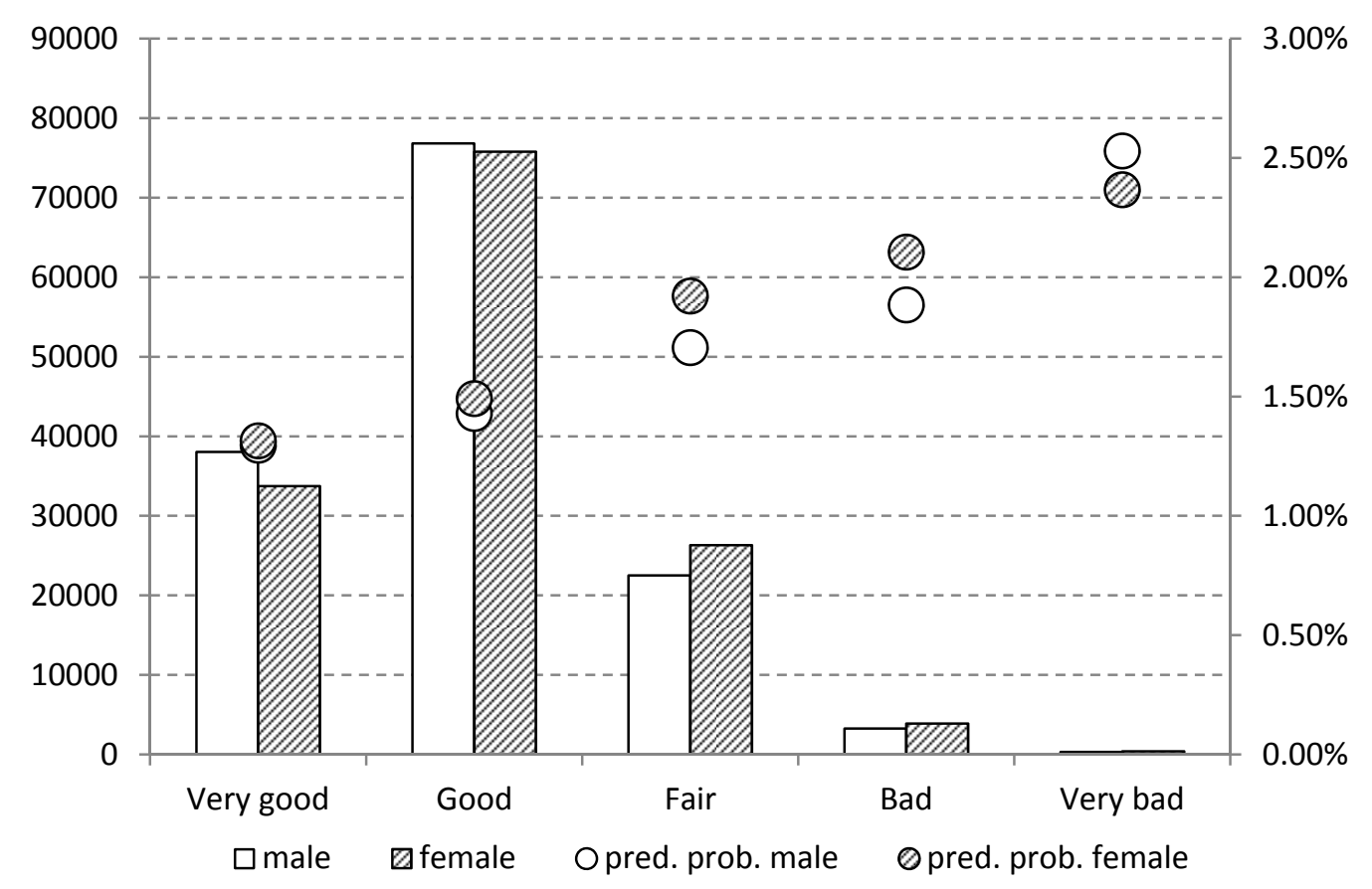

1d. Education

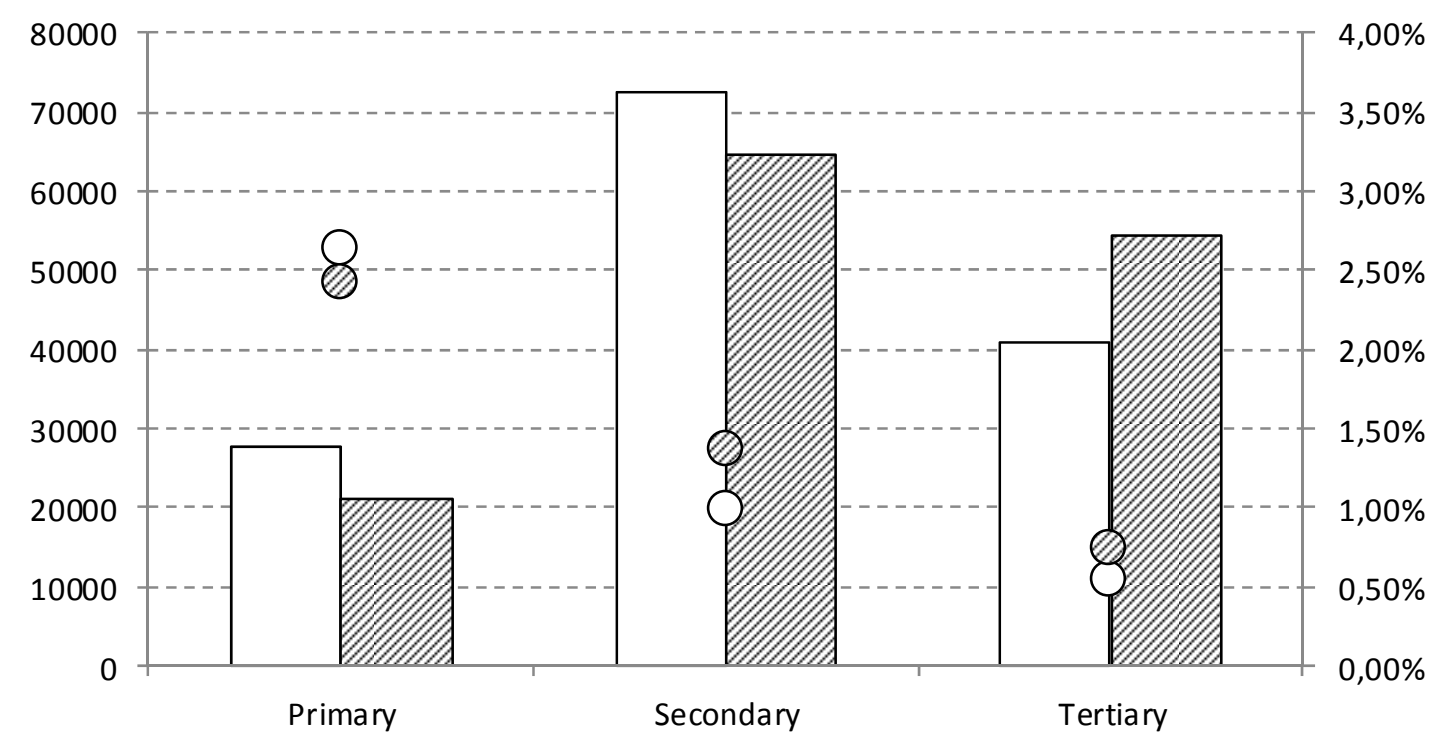

$\square$ male $\square$ female $\bigcirc$ pred. prob. male $\oslash$ pred. prob. female 
1e. Type of job

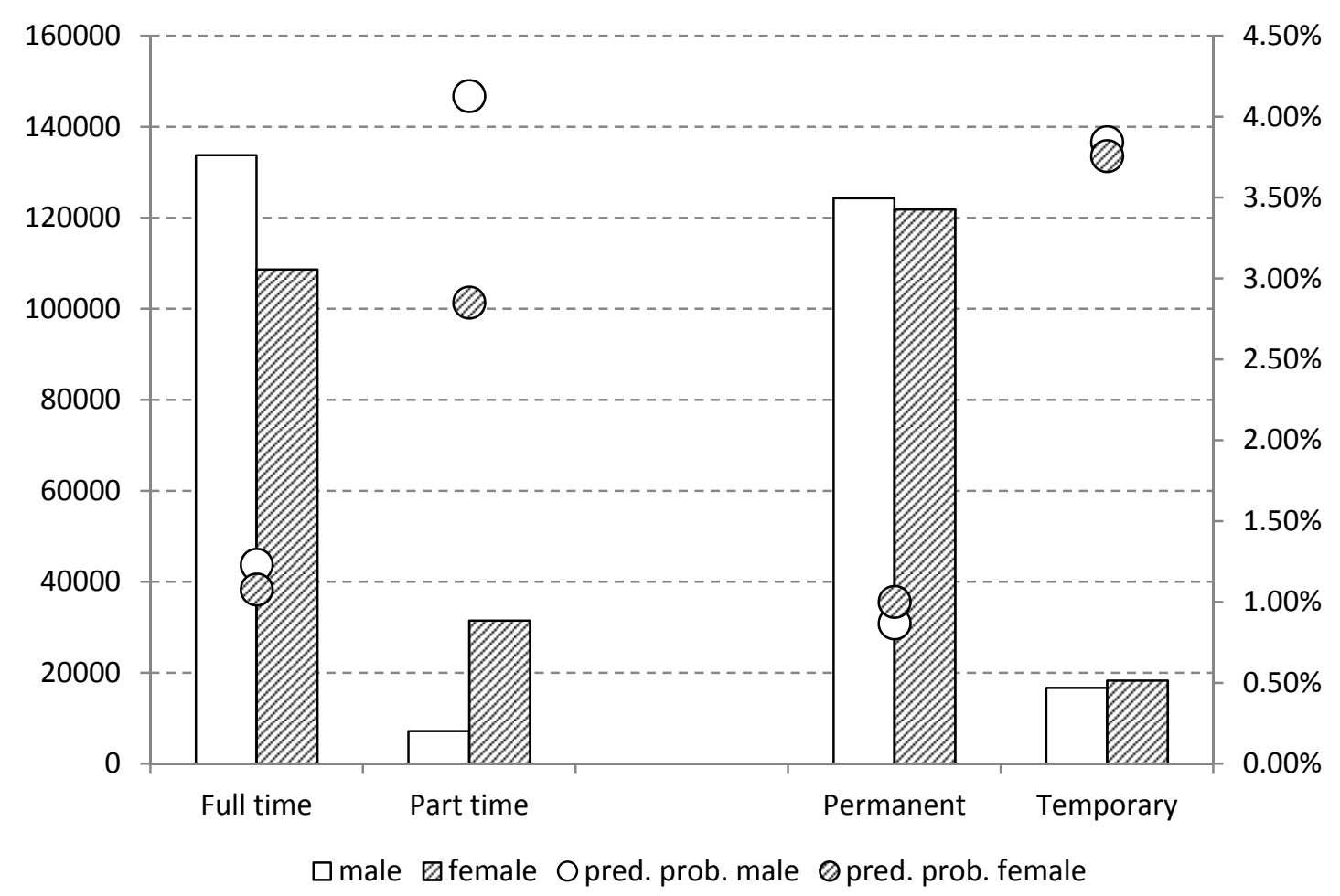

1f. Type of occupation

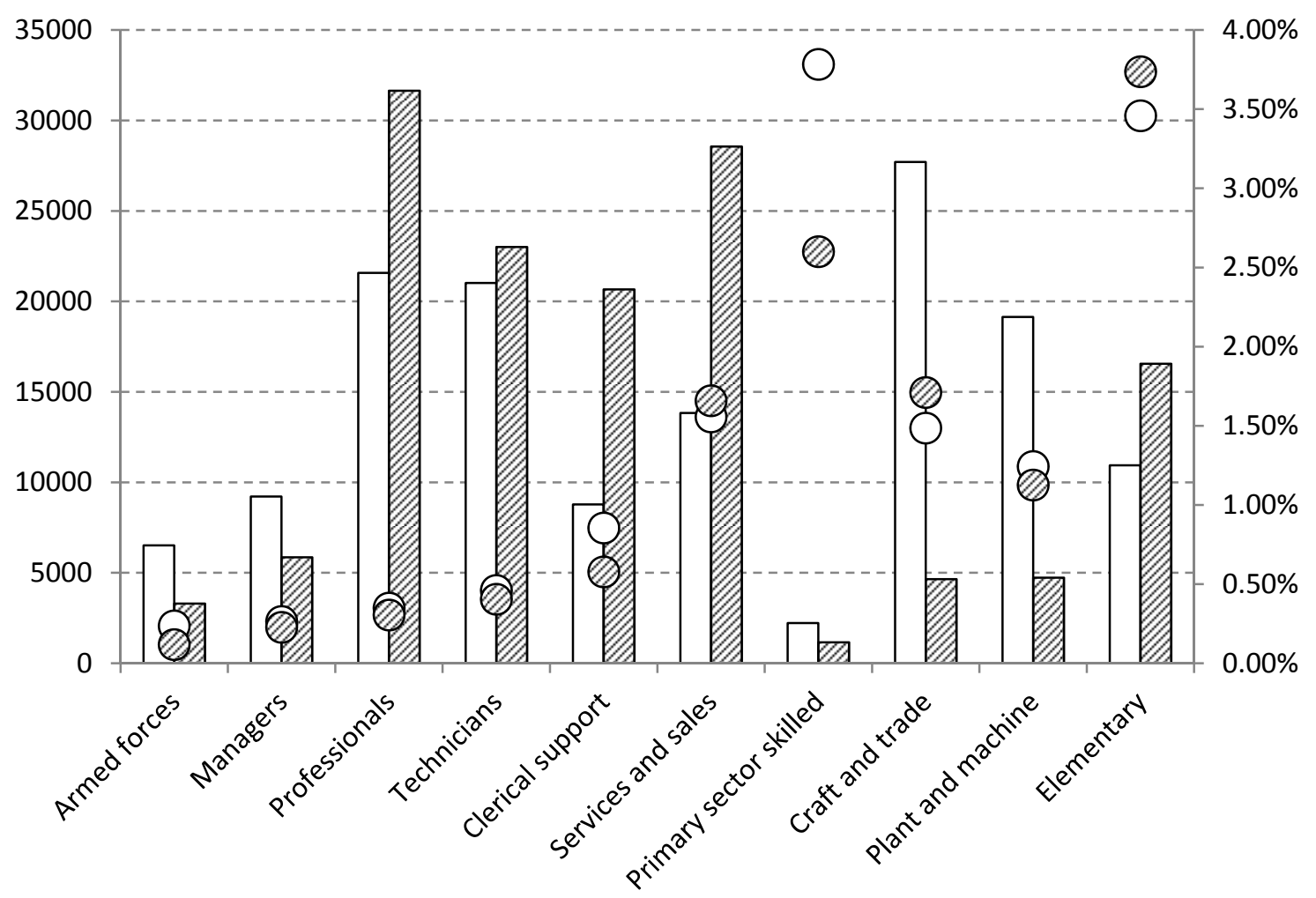

$\square$ male $\square$ female Opred. prob. male Opred. prob. female 
Figure 2. Distribution of the average probability attributed to each variable by categories 2a. Education

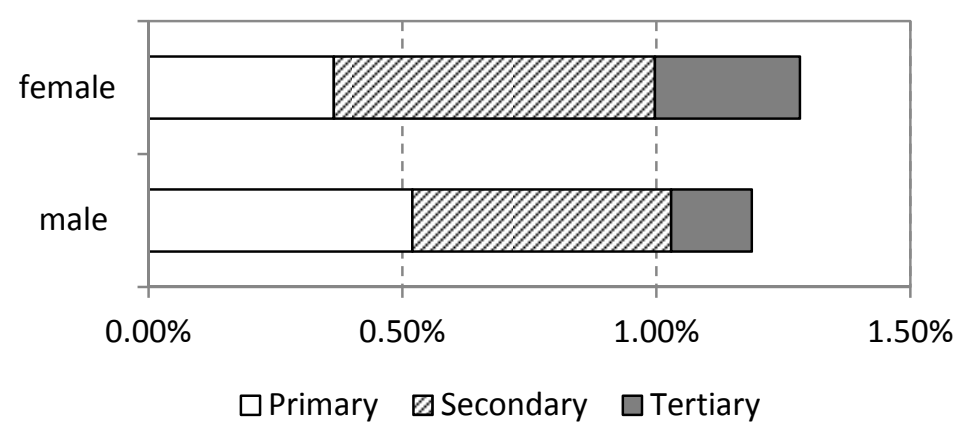

2b. Type of job

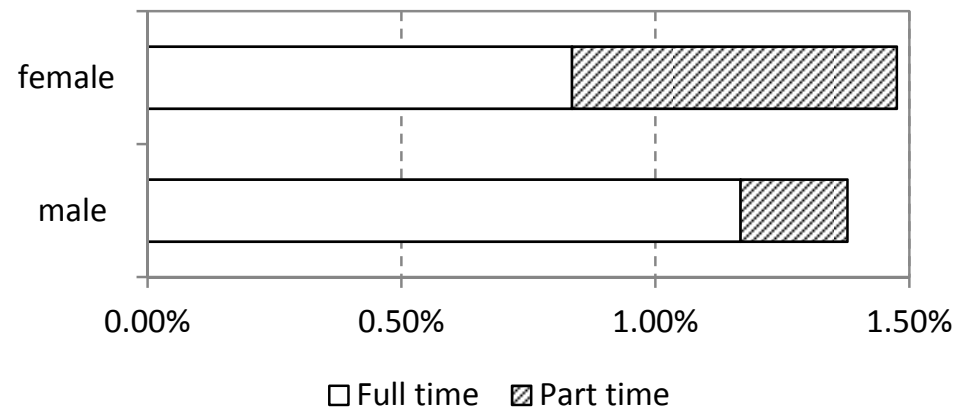

2c. Occupation

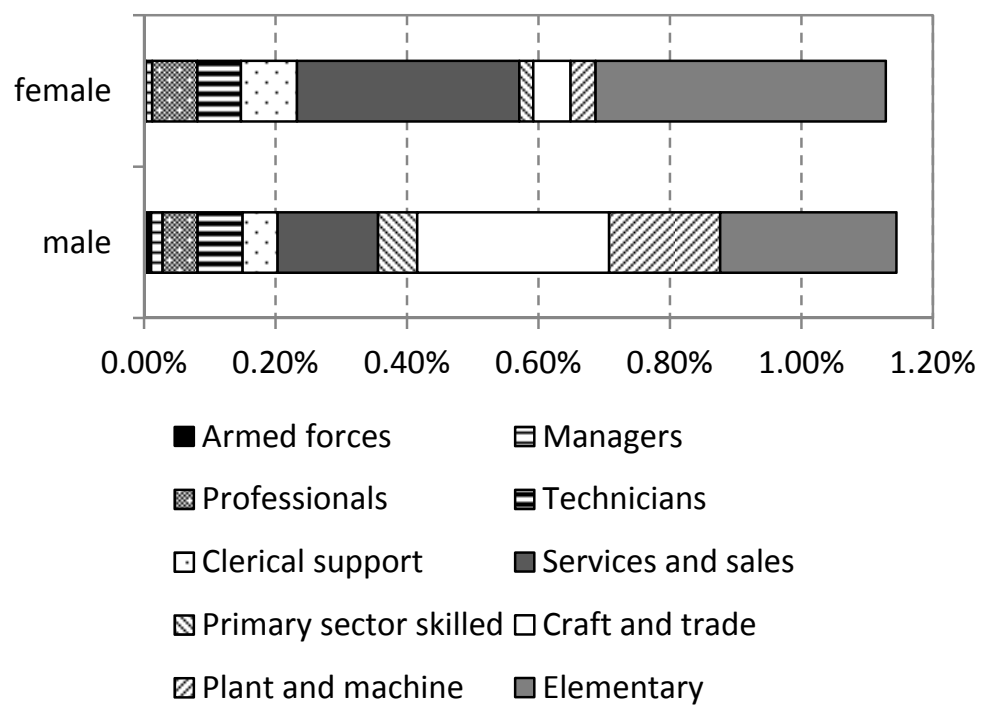


Figure 3. Education and the labour market

3a. Education of workers in part-time jobs

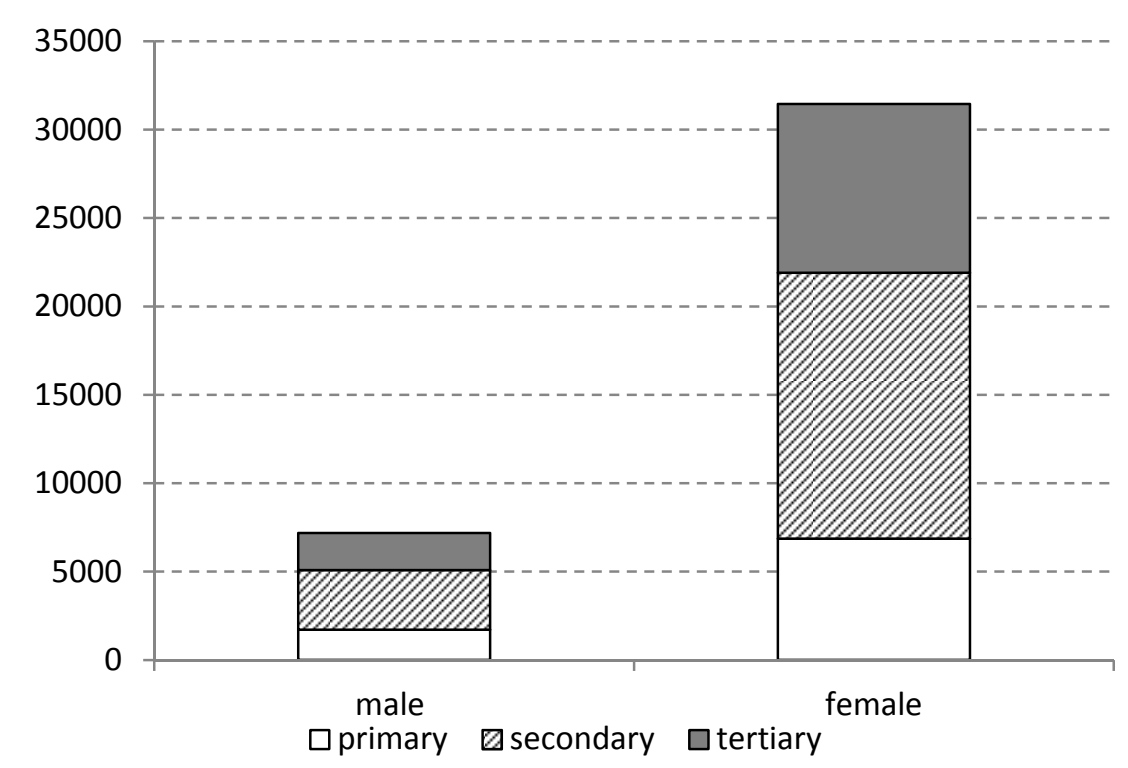

3b. Workers with tertiary education in sectors with the highest rates of poverty

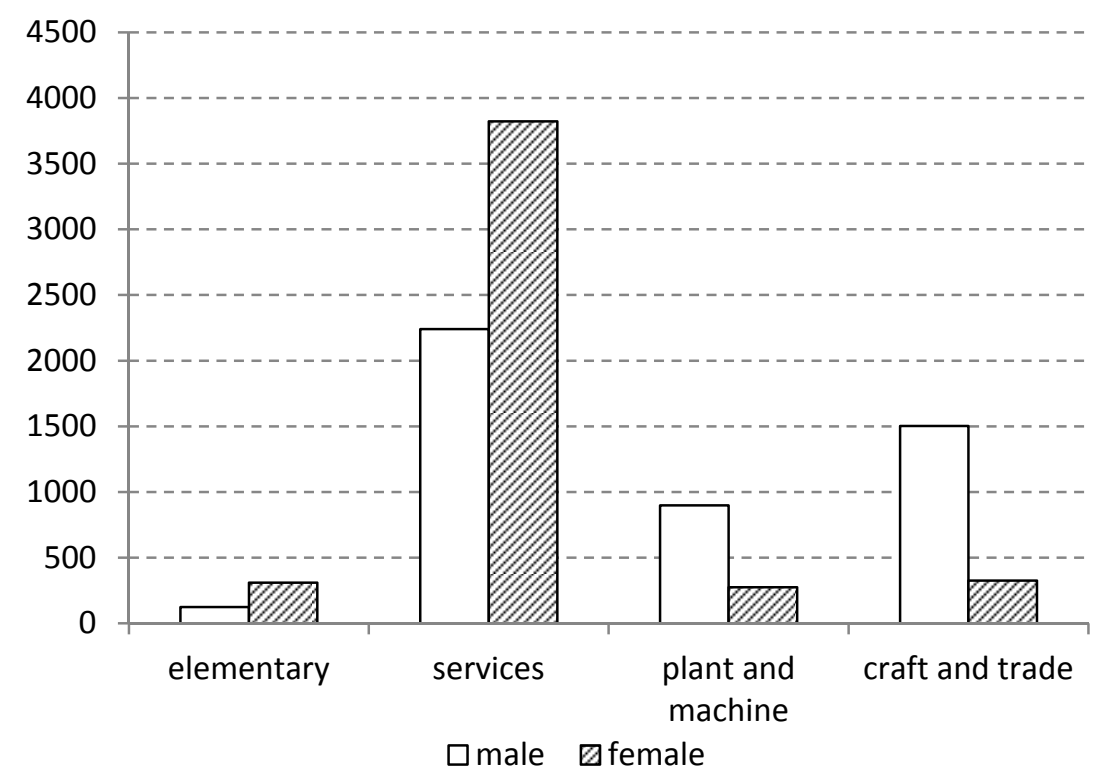

